\title{
PENGARUH MANAJEMEN PROGRAM YAYASAN \\ BERBASIS KEAGAMAAN TERHADAP MORAL PESERTA DIDIK \\ DI SMA DARUL FIKRI SUMANDA
}

\author{
Siti Masitoh, Muhtarom, Trufi Murdiani \\ stitpringsewu@gmail.com, muhtarom29@gmail.com, missmurdian1@gmail.com \\ STIT Pringsewu dan Fakultas Ekonomi dan Bisnis IIB Darmajaya
}

\begin{abstract}
ABSTRAK
Penelitian ini bertujuan untuk mendeskripsikan tentang pengaruh manajemen program yayasan berbasis keagamaan terhadap moral peserta didik di SMA Darul Fikri Sumanda Kecamatan Pugung Kabupaten Tanggamus. Pengumpulan data ini dilakukan dengan mengadakan pemberian angket, observasi, wawancara, dan dokumentasi. Analisis data yang digunakan adalah analisis data deskriptif. Adapun instrumen penelitiannya menggunakan uji validitas, uji reliabilitas, dan uji linieritas, yaitu untuk mengetahui pengaruh antara program yayasan berbasis keagamaan dengan moral peserta didik.

Pengaruh manajemen program yayasan berbasis keagamaan terhadap moral peserta yang meliputi: perencanaan, meliputi perencanaan program kepesantrenan, pengorganisasian, penerapan, pengawasan. Pada setiap bidang, pelaksanaan manajemen program yayasan berbasis keagamaan sudah dilaksanakan sesuai dengan program kerja yang direncanakan sehingga program yayasan berbasis keagamaan dapat tercapai. Adanya kerjasama antara ketua yayasan, kepala sekolah, dewan guru, wali siswa, dan siswa, sehingga program yayasan berbasis keagamaan dapat terlaksana. Hasil pelaksanaan manajemen program yayasan berbasis kegamaan berpengaruh dan efektiv terhadap moral peserta didik berdasarka perhitungan koefisien korelasi sederhana sebesar $88,36 \%$.
\end{abstract}

\section{Kata kunci : Manajemen, Moral, Peserta didik}

\section{ABSTRACT}

This study aims to describe the effect of the management of religious-based foundation programs on the morale of students in Darul Fikri Sumanda High School, Pugung District, Tanggamus Regency. This data collection is done by providing questionnaires, observations, interviews, and documentation. Analysis of the data used is descriptive data analysis. The research instrument uses a validity test, a reliability test, and a linearity test, which is to determine the effect of a religious-based foundation program with the morals of students.

The influence of foundation-based religious program management on the morale of participants which includes: planning, including boarding school program planning, organizing, implementing, monitoring. In each field, the implementation of the management of religious-based foundation programs has been carried out in accordance with the planned work programs so that the religious-based foundation programs can be achieved. There is cooperation between the chairman of the foundation, the principal, the council of teachers, student guardians, and students, so that the foundation-based religious program can be implemented. The results of the implementation of the management of the foundation program based on the effect of influence and effectiveness on the morale of students based on simple correlation coefficient calculation of $88.36 \%$.

Keywords: Management, Moral, Students 


\section{A. PENDAHULUAN}

Yayasan lahir karena suatu perbuatan hukum, yang tidak mempunyai anggota dan bertujuan untuk melaksanakan tujuan yang tertera dalam statistik yayasan dengan dana yang dibutuhkan untuk itu (Rasjid, 2001: 6).

Menurut Kusumastuti, dkk. (2001:18) menyatakan bahwa yayasan sebagai badan hukum telah diterima di Belanda dalam suatu yurisprudensi tahun 1882 Hoge Raad, yang merupakan badan peradilan tertinggi di negeri Belanda berpendirian bahwa yayasan sebagai badan hukum adalah sah menurut hukum dan karenanya dapat didirikan. Pendirian Hoge Raad tersebut diikuti oleh Hoode Gerech Shof di Hindia Belanda (sekarang Indonesia) dalam putusannya dari tahun 1889 .

Yayasan dipandang sebagai subyek hukum karena merupakan perkumpulan orang, dapat melakukan perbuatan hukum dalam hubungan hukum, mempunyai harta kekayaan sendiri, pengurus, maksud dan tujuan, kedudukan hukum (domisili) tempat dan dapat digugat atau menggugat di muka pengadilan (Syawie, 1993:89).

Yayasan dipandang dari unsur maksud dan tujuan mempunyai konsekuensi terhadap pengembangan masyarakat diluar anggota. Sebagaimana Pasal 1 Undang-Undang Nomor 16 Tahun 2001 tentang yayasan. Yaitu badan hukum yang terdiri atas kekayaan yang dipisahkan dan diperuntukkan untuk mencapai tujuan tertentu dibidang sosial keagamaan dan kemanusiaan yang tidak mempunyai anggota (Soeroedjo,1981: 4).

Bidang sosial, keagamaan dan kemanusiaan menjadi unsur penting sebagai dasar sebuah yayasan didirikan. Ketiga hal tersebut menjadi landasan yang kuat dalam menumbuhkan moral kehidupan bermasyarakat.

Menurut Ali dan Asrori (2012:136), Untuk mewujudkan kehidupan yang damai penuh keteraturan, ketertiban, dan keharmonisan diperlukan perilaku moral yang baik. apabila tingkah laku orang tersebut sesuai dengan nilainilai moral yang dijunjung tinggi oleh kelompok sosialnya maka dapat dikatakan sebagai seseorang yang bermoral (Yusuf LN, 2009:132).
Aspek psikologis, sosial, budaya. Baik yang terdapat dalam lingkungan keluarga, sekolah, maupun masyarakat. Kondisi psikologis, pola interaksi, pola kehidupan beragama, berbagai sarana rekreasi yang tersedia dalam lingkungan keluarga, sekolah, dan masyarakat menjadi faktor lingkungan yang berpengaruh terhadap perkembangan nilai moral dan sikap individu (Ali dan Asrori (2012:146).

Sedangkan indikator moral meliputi Religius, Jujur, Toleransi, Disiplin, Kerja keras, Kreatif, Mandiri, Demokratis, Rasa ingin tahu, Semanagat kebangsaan, Cinta tanah air, Menghargai prestasi, Bersahabat/komunikatif, Cinta damai, Gemar membaca, Peduli lingkungan, Peduli sosial, Tanggung jawab (Suyadi, 2013:8-9).

Untuk mencapai tujuan tersebut yaysan memerlukan manajemen dalam pengelolaanya sehingga tidak melencang dari maksud dan tujuan didirikanya yayasan.

Manajemen adalah kemempuan dan keterampilan khusus yang dimiliki oleh seseorang atau lembaga untuk melakukan suatu kegiatan baik secara perorangan ataupun bersama orang lain dalam upaya mencapai tujuan organisasi secara produktif, efektif, dan efesien (Komariah \& Mulyati, 2011: 86-87).

Menurut Stoner yang dikutip oleh Fauzi dalam bukunya (2013:5), yang berjudul Manajemenen Itu Mudah mengatakan bahwa manajaemen didefinisikan sebagai suatu proses perencanaan, pengorganisasian, memimpin dan mengawasi usaha-usaha dari anggota organisasi lainnya untuk mencapai tujuan organisasi yang telah ditetapkan. Wahjosumodjo, mengartikan manajemen sebagai proses merencanakan, memimpin dan mengendalikan usaha anggotaanggota organisasi serta pendayagunaan seluruh sumber daya organisasi dalam rangka mencapai tujuan yang ditetapkan (Wahjosumodjo, 2003: 93-94). 
Dari definisi di atas dapat disimpulkan bahwa manajemen merupakan suatu proses yang dilakukan oleh seseorang atau bersama orang lain agar suatu usaha dapat berjalan dengan baik setra memerlukan suatu perencanaan yang matang, agar tujuan yang dikehendaki dapat berjalan sesuai dengan apa yang diinginkan, serta memiliki pengorganisasian yang terorganisir dengan baik untuk mendukung suatu rencana yang telah ditetapkan dengan menempatkan sesorang sesuai dengan fungsi dan tugasnya agar dalam mencapai tujuan organisasi yang produktif, efektiv, serta efisien .

Penerapan manajemen yang baik akan berpengaruh terhadap tujuan dan arah dari setiap progrm yang ditetapkan oleh suatu lembaga atau yayasan.

SMA Darul Fikri Sumanda merupakan sekolah umum tingkat atas yang satu-satunya di Kabupaten Tanggamus, yang menerapkan kurikulum yang berbasis kepesantrenan selain menerapkan kurikulum yang telah ditetapkan oleh pemerintah. Akan tetapi siswa/siswi di SMA Darul Fikri Sumanda, masih kurang baik dari segi moral atau etikanya, ini terlihat ketika penulis melaksanakan kegiatan praktik pengalaman lapangan (PPL) di SMA Darul Fikri Sumanda pada bulan Oktober sampai dengan bulan Desember tahun 2016. Dari kegiatan PPL tersebut penulis melihat bahwa siswa/siswi SMA Darul Fikri Sumanda masih kurang baik dari segi moralnya salah satu contohnya tidak menghormati dan menghargai guru ketika sedang melaksanakan kegiatan belajar mengajar.

Para pendidik di SMA Darul Fikri Sumanda masih ada yang hanya memberikan pengajaran tentang pengetahuan (kognitif) saja, tidak mengajarkan tentang moralnya (afektiv). Hal ini terlihat ketika penulis melaksnakan kegiatan praktik pengalaman lapangan (PPL). Dan penulis telah mewawancarai salah satu siswi SMA Darul Fikri Sumanda yang bernama Siti Ayunah kelas XII pada hari rabu tanggal 01 Maret 2020, pada pukul 12.30. WIB. Adapun hasil wawancara penulis dengan siswa masih ada guru yang tidak memberikan pengarahan kepada siswa yang ribut ketika kegiatan belajar mengajar berlangsung, baik guru mata pelajaran umum atau guru mata pelajaran agama.

Melihat kondisi tersebut yayasan Darul Fikri Sumanda, khususnya di SMA Darul Fikri Sumanda menerapkan dan melaksanakan sebuah program yayasan yang berbasis keagamaan dengan tujuan agar siswa/siswi di SMA Darul Fikri Sumanda lebih mengetahui dan mendalami tentang pelajaran keagamaan dan diharapkan menjadi siswa/siswi yang memiliki moral atau etika yang baik
Program ini dilaksanakan setiap hari selasa sampai hari sabtu pada jam sekolah yaitu pada oukul 07.00-08.00 WIB dan sebelum kegiatan belajar mengajar berlangsung. Adapun program yayasan yang berbasis keagamaan di SMA Darul Fikri Sumanda yaitu program kepenatrenan diantaranya yaitu, syahril qur'an, serta mempelajari tentang kitab-kitab seperti Ta'lim Muta'im, Fikih, dan Nahu, yang berkaitan dengan keimanan, ketakwaan, dan tingkah laku (akhlak).

Dari hal tersebut peneliti ingin mengetahui apakah program yayasan yang berbasis keagamaan yang ada di SMA Darul Fikri Sumanda selama ini telah dimanejemen atau dikelola dengan baik atau belum, pengukuran baik tidaknya bisa dilihat dari pengaruh program yayasan yang dijalankannya terutama berpengaruh terhadap moral peserta didik.

Dari latar belakang di atas maka penulis mengambil judul yang berkaitan dengan program yayasan yang berhubungan dengan moral peserta didik yaitu "Pengaruh Manajemen Program Yayasan yang Berbasis Keagamaan terhadap Moral Peserta di SMA Darul Fikri Sumanda Tahun Pelajaran 2019/2020”.

\section{B. Tujuan Penelitian}

Tujuan yang diharapkan dalam penelitian ini adalah sebagai berikut:

1. Manajemen program yayasan yang berbasis keagamaan dapat berpengaruh terhadap nilai moral peserta didik.

2. Manajemen program yayasan yang berbasis keagamaan efektiv dan berpengaruh serta dapat memperbaiki moral peserta didik.

\section{METODE}

Dalam penelitian ini penulis menggunakan metode DISKRIPTIF kuantitatif. Data primer dalam penelitian ini adalah ketua yayasan, kepala sekolah, guru, dan siswa di SMA Darul Fikri Sumanda. SEDANGKAN Data sekunder dalam penelitian ini adalah dokumentasi. maka populasi dalam penelitian ini adalah seluruh siswa/siswi SMA Darul Fikri Sumanda Tahun Pelajaran 2016/2020. pengambilan sampel di atas dapat diambil populasi yang akan dijadikan sampel berdasarkan rumus formula slovin. Berdasarkan rumus penentuan sampel diperoleh data sampel sebagai berikut:

$$
\begin{aligned}
N & =108 / 108(0,05)^{2}+1 \\
& =0,0025 \times 0,27+1=1,27 \\
& =\frac{108}{1,27}=85,03
\end{aligned}
$$


Dibulatkan menjadi 85 orang siswa. Jadi pengambilan sampel berdasarkan populasi 108 orang siswa adalah 85 orang siswa. Cara yang digunakan untuk menguji instrumen pengambilan data menggunakan uji validitas dan realibilitas data. Sedangkan dalam menguji lineritas hubungan digunakan teknik uji $f$. Untuk analisis datanya menggunakan statistik deskriptif kuantitatif.

\section{PEMBAHASAN}

yayasan Darul Fikri Sumanda khususnya SMA Darul Fikri Sumanda, membuat suatu rencana dari program yayasan yang berbasis keagaman yaitu program kepesantrenan, yang menjadi kurikulum baru yang digunakan di SMA Darul Fikri Sumanda selain kurikulum yang telah ditetapkan. Program yayasan yang berbasis keagamaan ini dicetuskan oleh Bapak Iwan Ridwan, S.Fil.I. Selaku ketua yayasan Darul Fikri Sumanda. Adapun prosedur perencanaan program yayasan berbasis keagamaan yaitu sebagai berikut:

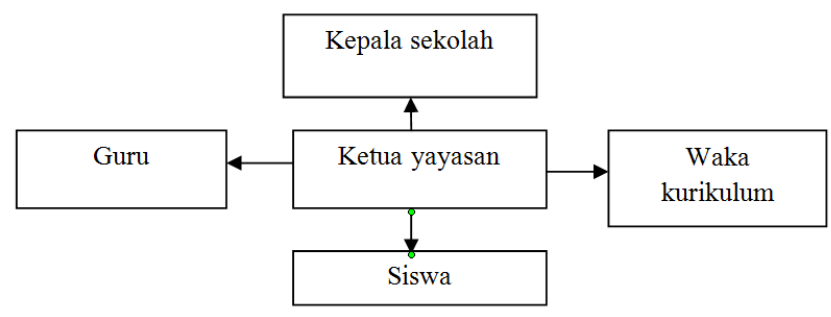

Perencanaan program yayasan berbasis keagamaan SMA Darul Fikri Sumanda dapat dibuktikan dengan perhitungan data dengan menggunakan SPSS 16.0 sebagai berikut:

Tabel 4.3 Hasil Data Penelitian Uji Instrumen Angket Manajemen Program Yayasan

\begin{tabular}{|c|c|c|}
\hline \multicolumn{3}{|c|}{ Uji Validitas } \\
\hline $\begin{array}{c}\text { No } \\
\text { Item }\end{array}$ & Signifikasi & Keterangan \\
\hline 1 & 0,435 & Valid \\
\hline 2 & 0,551 & Valid \\
\hline 3 & 0,549 & Valid \\
\hline 4 & 0,52 & Valid \\
\hline 5 & 0,436 & Valid \\
\hline 6 & 0,699 & Valid \\
\hline 7 & 0,684 & Valid \\
\hline 8 & 0,237 & Valid \\
\hline 9 & 0,432 & Valid \\
\hline 10 & 0,537 & Valid \\
\hline \multicolumn{3}{|c|}{ Uji Reliabilitas } \\
\hline No & Signifikasi & Keterangan \\
Item & & \\
\hline 1 & 0,570 & Sedang/cukup \\
\hline 2 & 0,570 & Sedang/cukup \\
\hline 3 & 0,570 & Sedang/cukup \\
\hline
\end{tabular}

\begin{tabular}{|c|c|c|}
\hline 4 & 0,570 & Sedang/cukup \\
\hline 5 & 0,570 & Sedang/cukup \\
\hline 6 & 0,570 & Sedang/cukup \\
\hline 7 & 0,570 & Sedang/cukup \\
\hline 8 & 0,570 & Sedang/cukup \\
\hline 9 & 0,570 & Sedang/cukup \\
\hline 10 & 0,570 & Sedang/cukup \\
\hline \multicolumn{3}{|c|}{ Uji Linieritas } \\
\hline $\begin{array}{c}\text { No } \\
\text { Item }\end{array}$ & Signifikasi & Keterangan \\
\hline 1 & 0,826 & Linier \\
\hline 2 & 0,826 & Linier \\
\hline 3 & 0,826 & Linier \\
\hline 4 & 0,826 & Linier \\
\hline 5 & 0,826 & Linier \\
\hline 6 & 0,826 & Linier \\
\hline 7 & 0,826 & Linier \\
\hline 8 & 0,826 & Linier \\
\hline 9 & 0,826 & Linier \\
\hline 10 & 0,826 & Linier \\
\hline
\end{tabular}

Sumber: Hasil pengolahan data SPSS 16.0

Berdasarkan tabel 4.3 diatas tentang angket manajemen program yayasan didapatkan hasil $\geq 0,05$ yang menyatakan bahwa data dikatakan valid. Hal tersebut akan diperjelas oleh gambar 1.2 dibawah ini.

Gambar 4.2. Diagram

Lingkaran Hasli Uji Instumen Angket Penelitian Program Yayasan

\section{Perencanaan Program Yayasan}

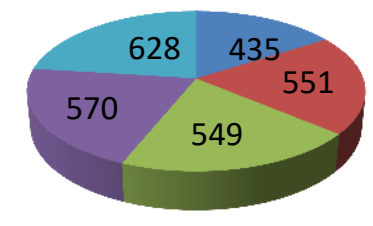

validitas

validitas

validitas

reliabilitas

- linieritas

Dari gambar diagram lingkaran di atas dapat disimpulkan bahwa data instumen angket penelitian program yayasan berbasis keagamaan di SMA Darul Fikri Sumanda adalah valid. Karena didapatkan hasil dengan taraf signifikasi $\geq 0,05$, dengan kategori perencanaan (Planning) signifikasi 0,551 (pertanyaan no 1), signifikasi 0,435 (pertanyaan no 2), dan signifikasi 0,549 (pertanyaan item no 3). Uji reliabilitas data berdasarkan reliability statistics Cronbach's Alpha signifikasi $\quad 0,570$ dalam kategori sedang/cukup.

Ketentuan koefisien $r$ menurut Arikunto (2006)

\begin{tabular}{|r|c|}
\hline Koefisien $\mathrm{r}$ & Reliabilitas \\
\hline $0,8000-1,000$ & Sangat tinggi \\
\hline
\end{tabular}




\begin{tabular}{|l|l|}
\hline $0,6000-0,7999$ & Tinggi \\
\hline $0,4000-0,5999$ & Sedang/cukup \\
\hline $0,2000-0,3999$ & Rendah \\
\hline $0,0000-0,1999$ & Sangat rendah \\
\hline
\end{tabular}

Uji linieritas data berdasarkan anova tabel didapatkan hasil berdasarkan sig. deviation from linearty adalah sebesar 0,826, dengan demikian angket penelitian program yayasan berbasis keagamaan dan moral peserta didik di SMA Darul Fikri Sumanda adalah linier.

1. Pengorganisasian (Organizing)

Setelah melakukan perncanaan, proses selanjutnya yaitu menyusun struktur organisasi kepengurusan, yang sesuai dengan tugas dan fungsi yang dijalankannya, tujuan dari pengorganisasian ini agar supaya rencana dari program yayasan yang berbasis keagamaan tersebut dapat tercapai dan terlaksana dengan baik.

Adapun srtuktur organisasi program yayasan yang berbasis keagamaan di SMA Darul Fikri Sumanda yaitu program kepesantrenan, dapat dilihat pada bagan dibawah ini

Gambar 4.3 Struktur Organisasi Program Yayasan

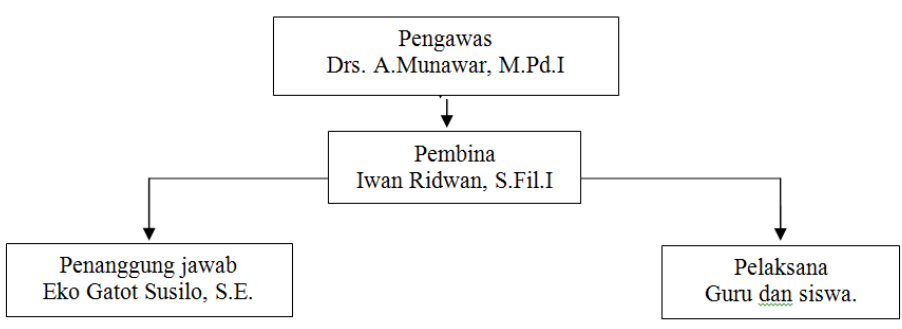

Sumber: TU SMA Darul Fikri Sumanda

Pengorganisasian program yayasan berbasis keagamaan dibuktikan dengan data penelitian dan data perhitungan dengan menggunakan SPSS 16.0 sebagai berikut:

Tabel 4.4 Hasil Data Penelitian Uji Instrumen Angket Manajemen Program Yayasan

\begin{tabular}{|c|c|c|}
\hline \multicolumn{3}{|c|}{ Uji Validitas } \\
\hline $\begin{array}{c}\text { No } \\
\text { Item }\end{array}$ & Signifikasi & Keterangan \\
\hline 1 & 0,435 & Valid \\
\hline 2 & 0,551 & Valid \\
\hline 3 & 0,549 & Valid \\
\hline 4 & 0,461 & Valid \\
\hline
\end{tabular}

\begin{tabular}{|c|c|c|}
\hline 5 & 0,436 & Valid \\
\hline 6 & 0,699 & Valid \\
\hline 7 & 0,684 & Valid \\
\hline 8 & 0,237 & Valid \\
\hline 9 & 0,432 & Valid \\
\hline 10 & 0,537 & Valid \\
\hline \multicolumn{3}{|c|}{ Uji Reliabilitas } \\
\hline $\begin{array}{c}\text { No } \\
\text { Item }\end{array}$ & Signifikasi & Keterangan \\
\hline 1 & 0,570 & Sedang/cukup \\
\hline 2 & 0,570 & Sedang/cukup \\
\hline 3 & 0,570 & Sedang/cukup \\
\hline 4 & 0,570 & Sedang/cukup \\
\hline 5 & 0,570 & Sedang/cukup \\
\hline 6 & 0,570 & Sedang/cukup \\
\hline 7 & 0,570 & Sedang/cukup \\
\hline 8 & 0,570 & Sedang/cukup \\
\hline 9 & 0,570 & Sedang/cukup \\
\hline 10 & 0,570 & Sedang/cukup \\
\hline \multicolumn{3}{|c|}{ Uji Linieritas } \\
\hline $\begin{array}{c}\text { No } \\
\text { Item }\end{array}$ & Signifikasi & Keterangan \\
\hline 1 & 0,826 & Linier \\
\hline 2 & 0,826 & Linier \\
\hline 3 & 0,826 & Linier \\
\hline 4 & 0,826 & Linier \\
\hline 5 & 0,826 & Linier \\
\hline 6 & 0,826 & Linier \\
\hline 7 & 0,826 & Linier \\
\hline 8 & 0,826 & Linier \\
\hline 9 & 0,826 & Linier \\
\hline 10 & 0,826 & Linier \\
\hline
\end{tabular}

Sumber: Hasil pengolahan data SPSS 16.0

Berdasarkan tabel 4.4 diatas tentang angket manajemen program yayasan didapatkan hasil taraf signifikasi $\leq 0,05$ yang menyatakan bahwa data tersebut valid. Hal tersebut akan diperjelas oleh gambar 4.4 dibawah ini. Gambar 4.4 Diagram Lingkaran Hasli Uji

Angket Penelitian Program Yayasan

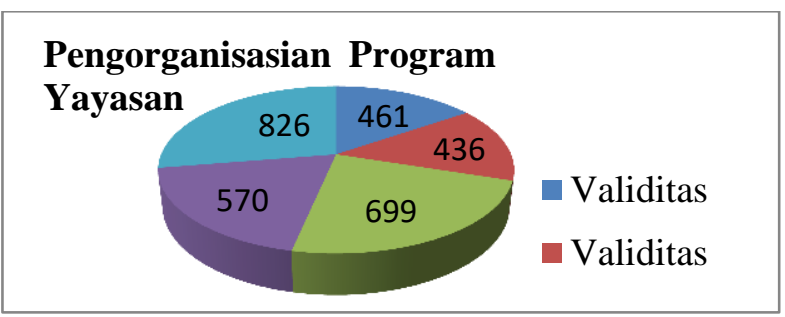


Dari gambar diagram lingkaran di atas dapat disimpulkan bahwa data instumen angket penelitian program yayasan berbasis keagamaan di SMA Darul Fikri Sumanda adalah valid karena taraf signifikasi $\leq 0.05$, dengan kategori pengorganisasian (Organizing) signifikasi 0,461 (pertanyaan item no 4), signifikasi 0,436 (pertanyaan item no 5), dan signifikasi 0,699 (pertanyaan item no 6). Uji reliabilitas data berdasarkan reliability statistics Cronbach's Alpha signifikasi 0,570 dalam kategori sedang/cukup.

Uji linieritas data berdasarkan anova tabel didapatkan hasil berdasarkan sig. deviation from linearty adalah sebesar signifikasi 0,826, dengan demikian angket penelitian program yayasan berbasis keagamaan di SMA Darul Fikri Sumanda adalah linier.

2. Pelaksanaan (Actuating)

Program yayasan yang berbasis keagamaan di SMA Darul Fikri Sumanda yaitu program kepesantrenan mulai dilaksanakan dan diterapkan pada tahun 2011 sampai dengan sekarang. Adapun pelaksanaannya yaitu dimulai pada hari Selasa sampai dengan hari Sabtu pada pukul 07.15-08.00 WIB. Adapun mata pelajaran dan jadwal pelajaran program yayasan berbasis keagamaan yaitu program kepesantrenan di SMA Darul Fikri Sumanda adalah sebagai berikut:

Tabel 4.5 Jadwal Pelajaran Program Kepesantrenan

\begin{tabular}{|c|c|c|c|c|}
\hline No & Hari & Waktu & $\begin{array}{c}\text { Mata } \\
\text { pelajaran }\end{array}$ & Guru \\
\hline 1 & Selasa & $\begin{array}{c}07.15- \\
08.00\end{array}$ & $\begin{array}{c}\text { Ta'lim } \\
\text { Muta'lim }\end{array}$ & Ust. Akim \\
\hline 2 & Rabu & $\begin{array}{c}07.15- \\
08.00\end{array}$ & Fikih & $\begin{array}{c}\text { Ust. Sukari } \\
\text { dan Ustdh } \\
\text { Sartinah }\end{array}$ \\
\hline 3 & Kamis & $\begin{array}{c}07.15- \\
08.00\end{array}$ & Nahu & Ust. Juned \\
\hline 4 & Jum'at & $\begin{array}{c}07.15- \\
08.00\end{array}$ & Fikih & $\begin{array}{c}\text { Ustdh } \\
\text { Sartinah }\end{array}$ \\
\hline 5 & Sabtu & $\begin{array}{c}07.15- \\
08.00\end{array}$ & $\begin{array}{c}\text { Syahril } \\
\text { Qur'an }\end{array}$ & $\begin{array}{c}\text { Ustdh } \\
\text { Laila }\end{array}$ \\
\hline
\end{tabular}

Sumber: TU SMA Darul Fikri Sumanda
Pelaksanaan program yayasan berbasis keagamaan di SMA Darul Fikri Sumanda dibuktikan dengan data penelitian dengan menggunakan instumen angket dan data dihitung dengan menggunakan SPSS 16.0 sebagai berikut:

Tabel 4.6 Hasil Data Penelitian Uji Instrumen Manajemen Program Yayasan

\begin{tabular}{|c|c|c|}
\hline \multicolumn{3}{|c|}{ Uji Validitas } \\
\hline No Item & Signifikasi & Keterangan \\
\hline 1 & 0,435 & Valid \\
\hline 2 & 0,551 & Valid \\
\hline 3 & 0,549 & Valid \\
\hline 4 & 0,461 & Valid \\
\hline 5 & 0,436 & Valid \\
\hline 6 & 0,699 & Valid \\
\hline 7 & 0,684 & Valid \\
\hline 8 & 0,237 & Valid \\
\hline 9 & 0,432 & Valid \\
\hline 10 & 0,551 & Valid \\
\hline \multicolumn{3}{|c|}{ Uji Reliabilitas } \\
\hline No Item & Signifikasi & Keterangan \\
\hline 1 & 0,570 & Sedang/cukup \\
\hline 2 & 0,570 & Sedang/cukup \\
\hline 3 & 0,570 & Sedang/cukup \\
\hline 4 & 0,570 & Sedang/cukup \\
\hline 5 & 0,570 & Sedang/cukup \\
\hline 6 & 0,570 & Sedang/cukup \\
\hline 7 & 0,570 & Sedang/cukup \\
\hline 8 & 0,570 & Sedang/cukup \\
\hline 9 & 0,570 & Sedang/cukup \\
\hline 10 & 0,570 & Sedang/cukup \\
\hline \multicolumn{3}{|c|}{ Uji Linieritas } \\
\hline No Item & Signifikasi & Keterangan \\
\hline 1 & 0,826 & Linier \\
\hline 2 & 0,826 & Linier \\
\hline 3 & 0,826 & Linier \\
\hline 4 & 0,826 & Linier \\
\hline 5 & 0,826 & Linier \\
\hline 6 & 0,826 & Linier \\
\hline 7 & 0,826 & Linier \\
\hline 8 & 0,826 & Linier \\
\hline 9 & 0,826 & Linier \\
\hline 10 & 0,826 & Linier \\
\hline
\end{tabular}

Sumber: Hasil pengolahan data SPSS 16.0 Berdasarkan tabel 4.7 diatas tentang angket manajemen program yayasan didapatkan hasil signifikasi $\geq$ 0.05 yang menyatakan bahwa data tersebut adalah valid. Hal tersebut akan diperjelas oleh gambar 4.5 dibawah ini.

Gambar 4.5 Diagram Lingkaran Hasli Uji Instumen Angket Penelitian Program Yayasan 


\section{Pelaksanaan Program Yayasan}

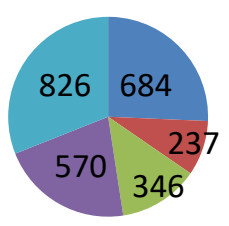

- Validitas

- Validitas

Validitas

- Reliabilitas

Dari gambar diagram lingkaran di atas dapat disimpulkan bahwa data instumen angket penelitian program yayasan berbasis keagamaan di SMA Darul Fikri Sumanda adalah valid karena taraf signifikasi $\geq 0,05$, dengan kategori pelaksanaan (Actuating) signifikasi 0.684 (pertanyaan item no 6), 0,237 (pertanyaan item no 7), dan signifikasi 0,346 (pertanyaan item no 8). Uji reliabilitas data berdasarkan reliability statistics Cronbach's Alpha signifikasi 0,570 dalam kategori sedang/cukup.

Uji linieritas data berdasarkan anova tabel didapatkan hasil berdasarkan sig. deviation from linearty adalah sebesar 0,826, dengan demikian angket penelitian program yayasan berbasis keagamaan di SMA Darul Fikri Sumanda adalah linier.

\section{Pengawasan (Controling)}

Pengadaan evaluasi dari program yayasan yang berbasis keagamaan yaitu program kepesantrenan bertujuan apakah program yayasan yang berbasis keagamaan di SMA Darul Fikri Sumanda terlaksana dengan baik atau belum, evaluasi ini biasanya dilakukan setiap persemester baik semester ganjil maupun semester genap. Adapun yang mengevaluasi program ini yaitu ketua yayasan sebagai penanggungjawab, kepala sekolah, dan dewan guru sebagai pelaksana.

Pengawasan serta pengevaluasian program yayasan berbasis keagamaan di SMA Darul Fikri Sumanda dibuktikan dengan penelitian dengan menggunakan instrument angket dan dihitung dengan menggunakan SPSS 16.0 sebagai berikut:

\begin{tabular}{|c|c|c|}
\hline \multicolumn{3}{|c|}{ Uji Validitas } \\
\hline $\begin{array}{c}\text { No } \\
\text { Item }\end{array}$ & Signifikasi & Keterangan \\
\hline 1 & 0,435 & Valid \\
\hline 2 & 0,551 & Valid \\
\hline 3 & 0,549 & Valid \\
\hline 4 & 0,461 & Valid \\
\hline 5 & 0,436 & Valid \\
\hline 6 & 0,699 & Valid \\
\hline 7 & 0,684 & Valid \\
\hline 8 & 0,237 & Valid \\
\hline 9 & 0,432 & Valid \\
\hline 10 & 0,547 & Valid \\
\hline \multicolumn{3}{|c|}{ Uji Reliabilitas } \\
\hline $\begin{array}{c}\text { No } \\
\text { Item }\end{array}$ & Signifikasi & Keterangan \\
\hline 1 & 0,570 & Sedang/cukup \\
\hline 2 & 0,570 & Sedang/cukup \\
\hline 3 & 0,570 & Sedang/cukup \\
\hline 4 & 0,570 & Sedang/cukup \\
\hline 5 & 0,570 & Sedang/cukup \\
\hline 6 & 0,570 & Sedang/cukup \\
\hline 7 & 0,570 & Sedang/cukup \\
\hline 8 & 0,570 & Sedang/cukup \\
\hline 9 & 0,570 & Sedang/cukup \\
\hline 10 & 0,570 & Sedang/cukup \\
\hline \multicolumn{3}{|c|}{ Uji Linieritas } \\
\hline $\begin{array}{c}\text { No } \\
\text { Item }\end{array}$ & Signifikasi & Keterangan \\
\hline 1 & 0,826 & Linier \\
\hline 2 & 0,826 & Linier \\
\hline 3 & 0,826 & Linier \\
\hline 4 & 0,826 & Linier \\
\hline 5 & 0,826 & Linier \\
\hline 6 & 0,826 & Linier \\
\hline 7 & 0,826 & Linier \\
\hline 8 & 0,826 & Linier \\
\hline 9 & 0,826 & Linier \\
\hline 10 & 0,826 & Linier \\
\hline
\end{tabular}

Sumber: Hasil pengolahan data SPSS 16.0 Berdasarkan tabel 4.8 diatas tentang angket manajemen program yayasan didapatkan hasil signifikasi $\geq$ 0,05 yang menyatakan bahwa data tersebut adalah valild. Hal tersebut akan diperjelas oleh gambar 4.6 dibawah ini.

Gambar 4.6 Diagram Lingkaran Hasli Uji Instumen Angket Penelitian Program Yayasan

\section{Pengawasan Program Yayasan}

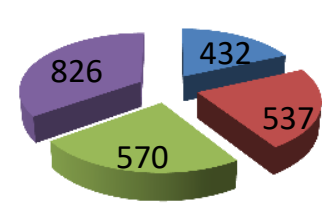

Validitas

- Validitas

Reliabilitas

- Linieritas 
Dari gambar diagram lingkaran di atas dapat disimpulkan bahwa data instumen angket penelitian program yayasan berbasis keagamaan di SMA Darul Fikri Sumanda adalah valid karena taraf signifikasi $\geq 0,05$, dengan kategori pengawasan (Controling) signifikasi 0,432 (pertanyaan item no 9), signifikasi 0,537 (pertanyaan item no 10). Uji reliabilitas data berdasarkan reliability statistics Cronbach's Alpha 0,570 dalam kategori sedang/cukup.

Uji linieritas data berdasarkan anova tabel didapatkan hasil berdasarkan sig. deviation from linearty adalah sebesar 0,826 dengan demikian angket penelitian program yayasan berbasis keagamaan di SMA Darul Fikri Sumanda adalah linier.

Untuk melihat hasil penelitian dari validitas data, reliabilitas data, dan linieritas data. data penelitian menggunakan SPSS 16.0 dapat dilihat pada lampiran 5, 6, dan 7 .

\section{G. Analisis dan Interpretasi Data}

Penelitian ini merupakan penelitian korelasional yang diddalamnya terdapat dua variabel yang diteliti. Variabel tersebut adalah manajemen program yayasan berbasis keagamaan (variabel $x$ ) sebagai variabel bebas, dan moral perserta didik (variabel y) variabel terikat. Untuk mengetahui pengaruh dari kedua variabel tersebut, penulis menggunakan rumus product moment yang dikembangkan oleh Karl Pearson dan uji t.

Tabel 4.8 Distribusi Varibel $x$ dan Variabel $y$

\begin{tabular}{|l|l|l|l|l|l|}
\hline Responden & $\mathrm{X}$ & $\mathrm{Y}$ & $\mathrm{Xy}$ & $\mathrm{X}^{2}$ & $\mathrm{Y}^{2}$ \\
\hline R_01 & 34 & 22 & 748 & 1156 & 484 \\
\hline R_02 & 35 & 19 & 665 & 1225 & 361 \\
\hline R_03 & 35 & 18 & 630 & 1225 & 324 \\
\hline R_04 & 31 & 20 & 620 & 961 & 400 \\
\hline R_05 & 32 & 24 & 768 & 1024 & 576 \\
\hline R_06 & 31 & 22 & 682 & 961 & 484 \\
\hline R_07 & 33 & 18 & 594 & 1089 & 324 \\
\hline R_08 & 31 & 19 & 589 & 961 & 361 \\
\hline R_09 & 34 & 22 & 748 & 1156 & 484 \\
\hline R_10 & 33 & 21 & 693 & 1089 & 441 \\
\hline R_11 & 34 & 21 & 714 & 1156 & 441 \\
\hline R_12 & 30 & 18 & 540 & 900 & 324 \\
\hline R_13 & 30 & 15 & 450 & 900 & 225 \\
\hline R_14 & 31 & 19 & 589 & 961 & 361 \\
\hline R_15 & 30 & 23 & 690 & 900 & 529 \\
\hline R_16 & 28 & 24 & 672 & 784 & 576 \\
\hline R_17 & 31 & 24 & 744 & 961 & 576 \\
\hline R_18 & 18 & 30 & 540 & 324 & 900 \\
\hline R_19 & 21 & 22 & 462 & 441 & 441 \\
\hline R_20 & 29 & 22 & 638 & 841 & 484 \\
\hline & & & & &
\end{tabular}

\begin{tabular}{|l|l|l|l|l|l|}
\hline R_21 & 29 & 23 & 667 & 841 & 529 \\
\hline R_22 & 27 & 22 & 549 & 729 & 484 \\
\hline R_23 & 28 & 22 & 616 & 784 & 484 \\
\hline R_24 & 30 & 23 & 690 & 900 & 529 \\
\hline R_25 & 28 & 24 & 672 & 784 & 576 \\
\hline R_26 & 26 & 23 & 598 & 676 & 529 \\
\hline R_27 & 28 & 22 & 616 & 784 & 484 \\
\hline R_28 & 27 & 19 & 513 & 729 & 361 \\
\hline R_29 & 28 & 24 & 672 & 784 & 576 \\
\hline R_30 & 26 & 27 & 702 & 676 & 729 \\
\hline R_31 & 26 & 23 & 598 & 676 & 529 \\
\hline R_32 & 27 & 24 & 648 & 729 & 576 \\
\hline R_33 & 24 & 25 & 600 & 576 & 625 \\
\hline \multirow{3}{*}{ Jumlah } & $\sum \mathrm{x}$ & $\Sigma \mathrm{y}$ & $\sum \mathrm{xy}$ & $\sum \mathrm{x}$ & $\sum \mathrm{y}$ \\
\cline { 2 - 6 } & 983 & 714 & 21,154 & 29,547 & 15,650 \\
\hline & & & &
\end{tabular}

$$
\begin{array}{ll}
\mathrm{N} \cdot \Sigma \mathrm{YX}=698,082 & \mathrm{~N} \cdot \Sigma \mathrm{y}^{2}=516,450 \\
\Sigma \mathrm{X} \cdot \Sigma \mathrm{Y}=701,862 & (\Sigma \mathrm{X})^{2}=966,289 \\
=975,051 & (\Sigma \mathrm{Y})^{2}=509,796
\end{array}
$$

N. $\Sigma \mathrm{X}^{2}=975,051$

$$
\begin{aligned}
& r_{x y}=\frac{N \Sigma X Y(\Sigma X)(\Sigma Y)}{\sqrt{N\left\{\Sigma X^{2}-(\Sigma X)^{2}\right\} N\left\{\Sigma Y^{2}-(\Sigma Y)^{2}\right\}}} \\
& r_{x y}= \\
& 33(21,154)-(938)(714) \\
& \sqrt{33(29.547)-(983)^{2} 33(15,630)-(714)^{2}} \\
& r_{x y}=\frac{698,082-701.862}{\sqrt{2.107 .240-2.056 .556}} \\
& r_{x y} \quad=\frac{50,884}{\sqrt{975.051 .966 .289 \sqrt{884}}} \\
& r_{x y} \quad=\frac{50.884}{(146,30)(225.58)} \\
& r_{x y} \quad=\frac{50,884}{33,001,60} \\
& r_{x y}=0,94 \\
& \mathrm{t} \quad=\underline{\sqrt{n-2}} \\
& \sqrt{1-r^{2}} \\
& =0,94 \underline{\sqrt{3,3-2}} \\
& \sqrt{1}(0,94)^{2} \\
& =\underline{0,96(5,57)} \\
& \sqrt{0,06} \\
& =\underline{5,2385} \\
& \sqrt{0,06} \\
& =\underline{5,2383} \\
& 0,245 \\
& \mathrm{t}=21,37 \\
& \text { df } \quad=\mathrm{N}-2 \\
& =95 \% \text { hasil diperoleh dari tabel } \\
& \mathrm{t}_{\text {tabel }}=1,697
\end{aligned}
$$

kemudian mencari determinasi :

$$
\begin{aligned}
\mathrm{r}^{2} & =(094)^{2} \\
& =0,8836 \\
& =88,36 \%
\end{aligned}
$$


Berdasarkan tabel 4.8 di atas serta perhitungan dari koefisien determinasi diperoleh $\mathrm{KD}=88,36 \%$. Dengan demikian besarnya pengaruh manajemen program yayasan berbasis keagamaan terhadap moral peserta didik sebesar $88,36 \%$. Akan tetapi masih ada faktor-faktor lain sebesar $100 \%$ $88,36 \%=11,64 \%$ yang dapat mempengaruhi moral peserta didik selain manajemen program yayasan berbasis keagamaan.

\section{DAFTAR PUSTAKA}

Chatama Rasjid, (2001), Tujuan Sosial Yayasan dan Kegiatan Usaha Bertujuan Laba. Bandung: PT. Citra Ditya Bakti.

Arie Kusumastuti Maria Suhardiadi, Hukum Yayasan di Indonesia Berdasarkan Undang- Undang RI No. 16 Tahun 2001, TentangYayasan, (Indonesia Center Publishing).

Hisbullah Syawie, Aspek-aspek Hukum Mengenai Yayasan di Indonesia, (Varian Pendidikan, Tahun IX, No. 98 November 1993).

Hayati Soeroedjo, Status Hakim Yayasan Dalam Kaitannya Dengan Penataan Badan- badan Usaha di Indonesia, Makalah pada Temu kerja Yayasan : Status Badan Hukum dan Sifat Wadahnya, Jakarta, 15 Desember 1981.

Mohammad Ali dan Mohammad Asrori, (2012). Psikologi Remaja; Perkembangan Peserta Didik, Jakarta: PT Bumi Aksara).

Syamsul yusuf LN, (2009), Psikologi Perkembangan Anak \& Remaja, Bandung :PT remaja rosdakarya bandung.

Suyadi, (2013). Strategi Pembelajaran Pendidikan Karakter, Bandung: Remaja Rosdakarya.

Aan Komariah, Yati Siti Mulyati, (2011), Manajemen Pendidikan. Bandung: Alfabeta.

Fauzi, (2013), Manajemen Itu Mudah, Depok: PT Raja Grafindo Persada.
Wahjosumodjo, (2003), Kepemimpinan Kepala Sekolah, Tinjauan Teoritik dan Permasalahannya. Jakarta:Raja Grafindo Persada.

Siti Ayunah, Wawancara dengan Penulis (Sumanda: SMA Darul Fikri), pada hari Rabu tanggal 01 Maret 2020. 